\title{
Evaluation of Difference in Healing of Gingival Tissue after Frenectomy Done by Laser as Compared to Conventional Surgical Technique: A Case Study
}

\author{
Avnika Garg ${ }^{1}$, Pooja Mehra², Baljeet Singh ${ }^{3}$
}

\begin{abstract}
The frenum is a fold of mucous membrane that attaches the lip and the cheek with the alveolar mucosa, the gingiva, and the underlying periosteum. The labial frenum may jeopardize the gingival health when it impedes oral hygiene, or when it is attached too closely to the gingival margin, thus, resulting in the formation of diastema between anterior teeth and/or traction of the attached gingiva. The management of such an aberrant frenum can be accomplished by performing a frenectomy procedure using different techniques with different outcomes of healing. Here, in the present study, healing after frenectomy performed using a laser has been compared to healing after frenectomy done using conventional surgical technique.

Keywords: Aberrant frenum, Frenum, Laser, Scalpel.

International Journal of Experimental Dental Science (2019): 10.5005/jp-journals-10029-1190
\end{abstract}

\section{INTRODUCTION}

The labial frenum is an anatomical landmark that joins the lips and cheeks with the maxillary and mandibular alveolar processes. The frenum is a mucous membrane fold that consists of connective tissue comprising of elastic and collagen fibers and sometimes, muscular fibers originating from the orbicularis. This fold, which is covered by stratified epithelium contains vascular structures with thin peripheral nervous ramifications. 'Ideally, the insertion of the frenum should be located at the level of the mucogingival junction, such that it does not interfere with the adhesion of the attached gingiva; however, clinically, a number of conditions are observed related to the frenum's insertion. ${ }^{1,2}$ Placek et al. classified the frenum based on its anatomical situ of insertion: Mucosal, gingival, papillary, or penetrating. . $^{3,4}$

Regardless of its anatomy, if a frenum has an insertion, which is potentially harmful, then it is considered as an anomalous frenum. ${ }^{2}$ For example, the maxillary labial frenum may retract the gingival margin, create a diastema, limit movement of lip, and produce a high smile line. ${ }^{5}$ Thus, failure to diagnose pathological insertion of the frenum may lead to certain developmental anomalies in the maxillary anterior region (like the fusion of the premaxilla) of neonatal or youth patients. ${ }^{6,7}$ This aberrant frenum can be treated by mucogingival procedures, frenectomy which is the complete removal of the frenum including its attachment to the underlying bone, or by, frenotomy which is the incision and the relocation of the frenal attachment. ${ }^{8}$

Frenectomy procedure can be performed by the routine scalpel technique, electrosurgery or by using lasers. The most practiced conventional technique involves excision of the frenum by using a scalpel; however, it carries the routine risks of surgery like bleeding and patient discomfort. Recently, with the introduction of lasers, it has been reported as a safe and effective for frenectomy procedures as it offers advantages of a shorter duration of the surgery, simplicity of the procedure, hemostatic control, the absence of postoperative infections, less pain, swelling and the presence of a small or no scar. ${ }^{9}$
${ }^{1}$ Department of Periodontology, Himachal Dental College, Sundarnagar, Himachal Pradesh, India

${ }^{2}$ Department of Periodontology, Baba Jaswant Singh Dental College and Hospital, Ludhiana, Punjab, India

${ }^{3}$ Department of Periodontology, Bhojia Dental College and Hospital, Baddi, Himachal Pradesh, India

Corresponding Author: Avnika Garg, Department of Periodontology, Himachal Dental College, Sundarnagar, Himachal Pradesh, India, Phone: +91 9915629767, e-mail: avnika.garg@gmail.com

How to cite this article: Garg A, Mehra P, Singh B. Evaluation of Difference in Healing of Gingival Tissue after Frenectomy Done by Laser as Compared to Conventional Surgical Technique: A Case Study. Int J Experiment Dent Sci 2019;8(2):38-41.

Source of support: Nil

Conflict of interest: None

Thus, the present study was done with an aim to compare healing after frenectomy performed using a laser as compared to healing after frenectomy done using the conventional surgical technique.

\section{Case Descriptions}

\section{Case 1: Frenectomy Done with Conventional Surgery}

A 26-year-old female patient was referred to the Department of Periodontology, Bhojia Dental College and Hospital, Baddi, Himachal Pradesh, in 2014, with a chief complaint of spacing between maxillary central incisors and unacceptable esthetics (Fig. 1). The patient was in excellent general health with no significant history of allergies, medications, or tobacco. After clinical examination, the abnormal maxillary labial frenum was detected visually by the blanching test, i.e., by applying tension over the frenum to see the movement of the papillary tip (Fig. 2). On examination, the attached gingiva was found to be inadequate for maxillary

(c) The Author(s). 2019 Open Access This article is distributed under the terms of the Creative Commons Attribution 4.0 International License (https://creativecommons. org/licenses/by-nc/4.0/), which permits unrestricted use, distribution, and non-commercial reproduction in any medium, provided you give appropriate credit to the original author(s) and the source, provide a link to the Creative Commons license, and indicate if changes were made. The Creative Commons Public Domain Dedication waiver (http://creativecommons.org/publicdomain/zero/1.0/) applies to the data made available in this article, unless otherwise stated. 


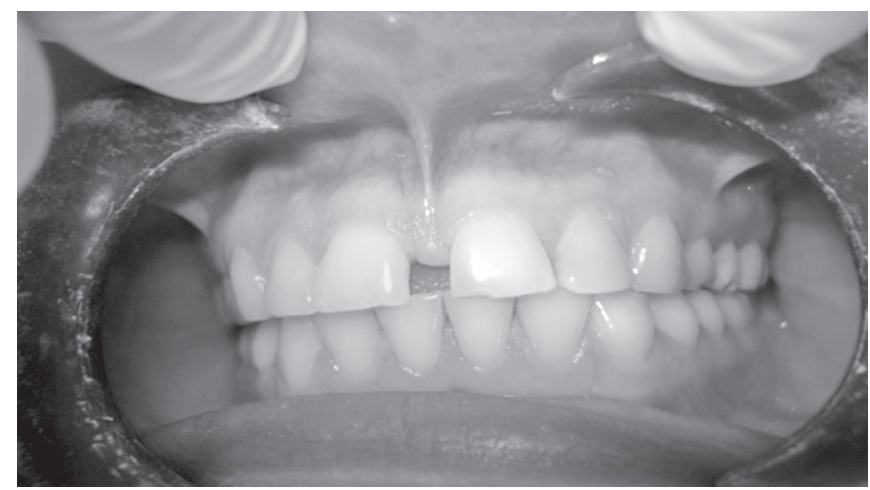

Fig. 1: Patient with spacing between maxillary incisors

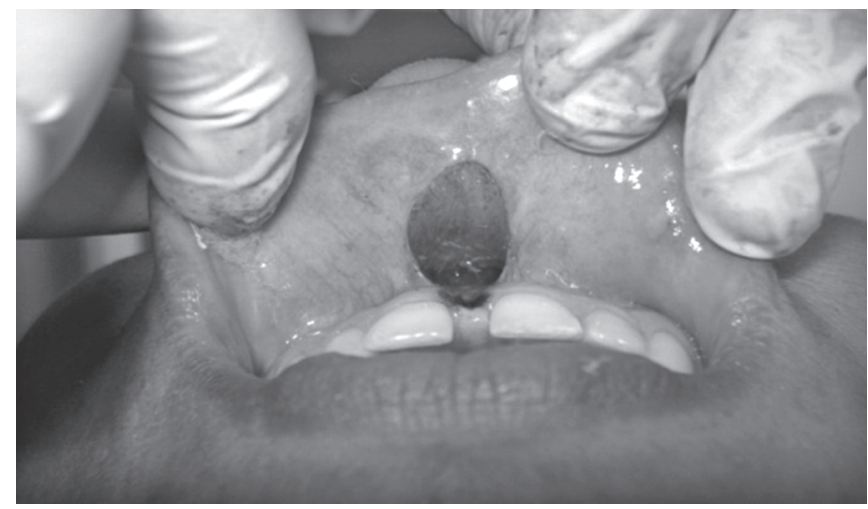

Fig. 3: Surgery done with conventional surgical technique

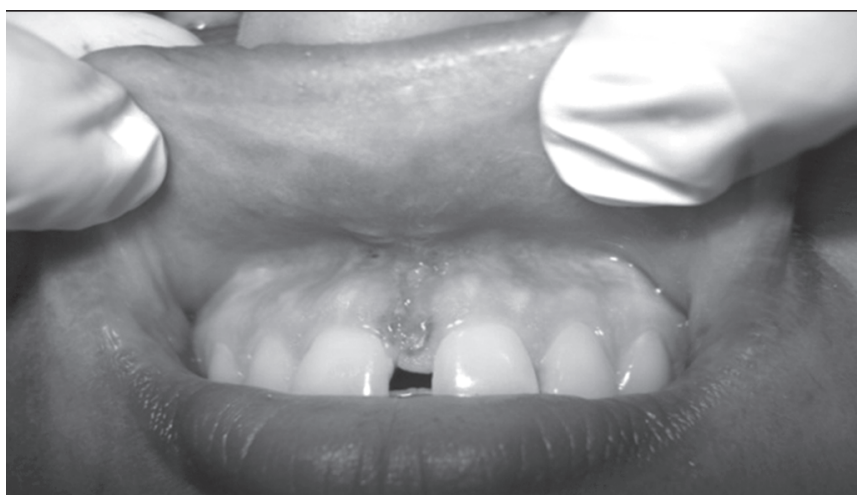

Fig. 5: Sutures removed after 1 week

central incisors. After bilateral infraorbital block was given with local anesthesia (2\% lignocaine with 1:100,000 adrenalin), surgery consisted of a V-shaped incision of the margins of the frenum, thus moving the apex of the frenum to a more apical position (Fig. 3). Horizontal and vertical incisions were made in the fibers attached to the periosteum, followed by the placement of one or two sutures (Fig. 4). The entire procedure took 15-20 minutes. Sutures were removed after 1-week postoperatively (Fig. 5). Postoperative healing was seen after 1-week and 1-month.

\section{Case 2: Frenectomy Done with Laser}

A 42-year-old male patient reported to the Department of Periodontology, Bhojia Dental College and Hospital, Baddi, Himachal Pradesh, in 2014 with a chief complaint of spacing

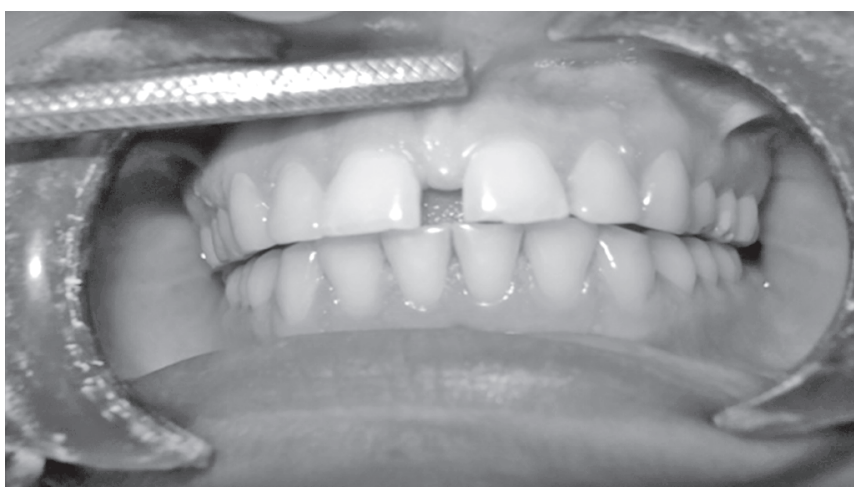

Fig. 2: Tension (blanch) test performed between central incisors

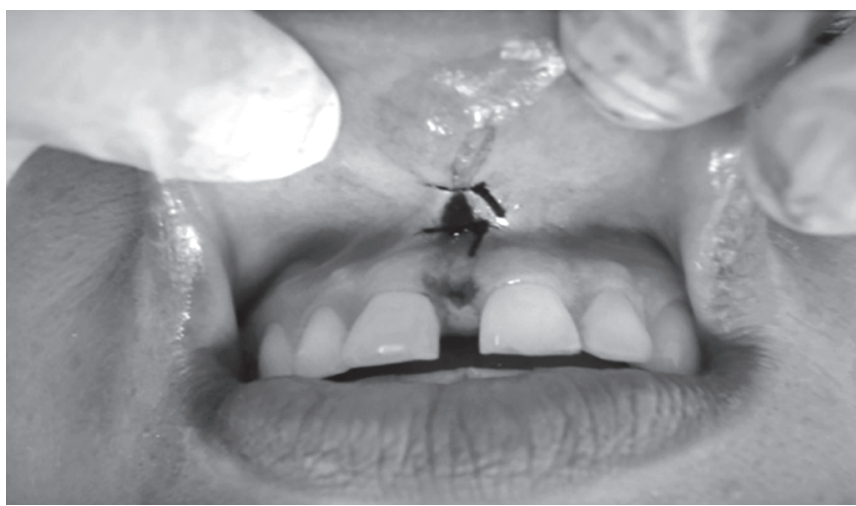

Fig. 4: Sutures placed technique in a V-shaped incision

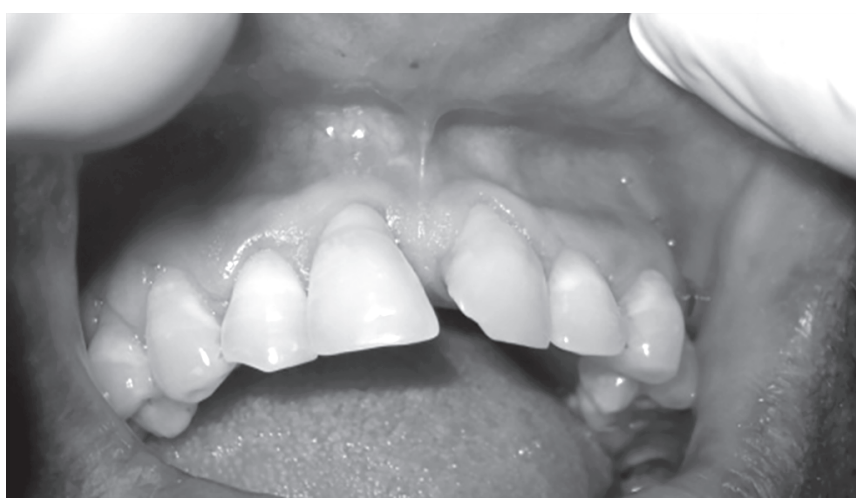

Fig. 6: Patient with spacing between two maxillary central incisors

between two central incisors (Fig. 6). The patient had excellent general health with no known history of allergies, medication, or tobacco. After clinical indications for surgery were determined (Fig. 7), a frenectomy was performed for maxillary labial frenum using a diode laser at $810 \mathrm{~nm}$ wavelength and 1.5 watts. Local infiltration from $2 \mathrm{~mL}$ of local anesthetic was used (2\% lignocaine with 1:100,000 adrenalin). The first incision was made along the axis of the frenum in the sagittal plane, continuing with a V-design, which followed the frenum insertion (Fig. 8), and finally, a light incision was made along the mucogingival junction of the periosteum. The procedure was completed with horizontal vaporizations to dislocate the connective fibers (Fig. 9); the entire process took 7-10 minutes. No sutures were required, and patient was recalled after 1-week (Fig. 10) and 1-month postoperatively. 


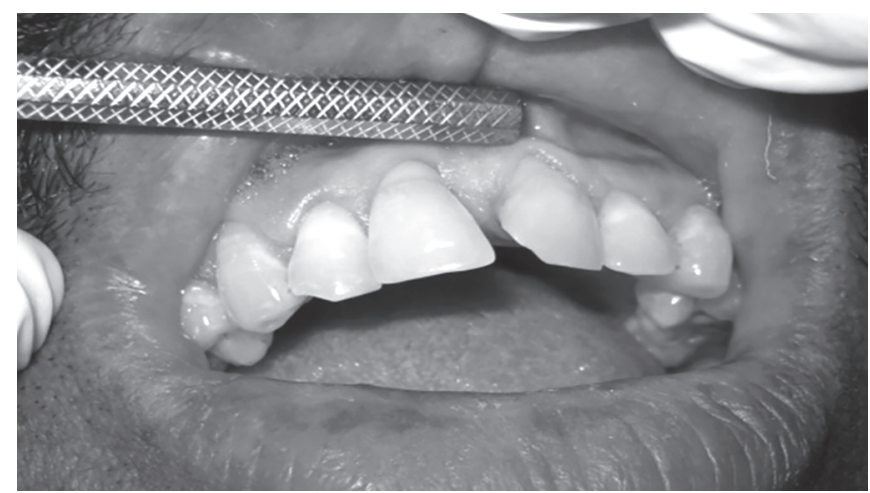

Fig. 7: Tension (blanch) test positive

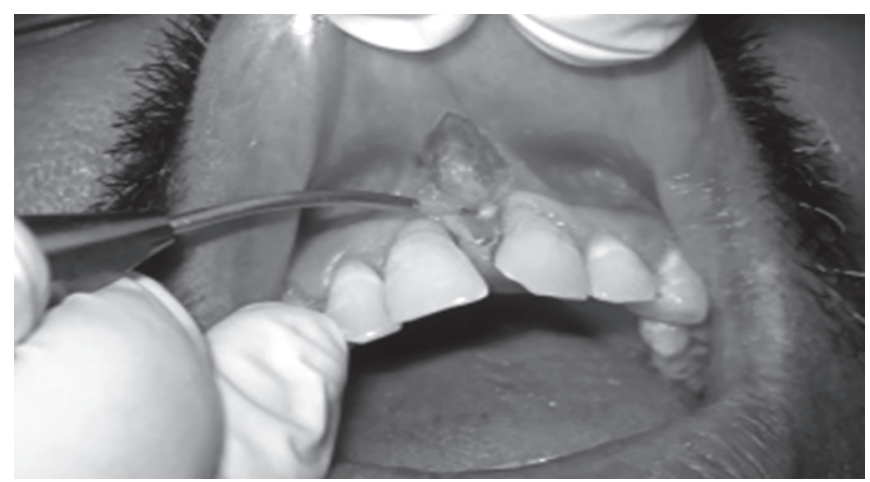

Fig. 9: Horizontal connective tissue fibers removed

Both the patients received the same postoperative instructions, which included a soft and cold diet for the meal immediately following surgery and avoiding spicy foods for 24 hours after the surgery. Anti-inflammatory analgesics (NSAIDs) were not necessary for both cases. Both the patients were instructed to perform usual daily oral hygiene procedures for the whole mouth but, avoiding the treated area. Rinses with $0.2 \%$ chlorhexidine mouthwash, twice a day, were prescribed to both patients for seven days postoperatively. Follow-up visits were conducted at 7 and 30 days posttreatment. At these visits, the treated areas were checked for soft tissue appearance, any adverse events (including functional complications), or any other symptoms reported by the patients.

\section{Results}

At each postoperative visit, the patients reported no postinterventional pain, bleeding, scar formation, or any other adverse event. In addition, clinicians did not observe any undesirable clinical findings for both the procedures. In conventional surgical technique, healing occurred by primary intention as the margins of the wound were approximated by the sutures. Whereas, in frenectomy performed with laser, the healing process of the wound occurred by secondary intention since the wound margins were not close to each other.

\section{Discussion}

Mucous folds or frena are normally found between the central incisors and in the canine premolar area of the maxillary and mandibular alveolar mucosa. ${ }^{10} \mathrm{~A}$ hypertrophic, fibrotic, ample, fan-shaped, or bifid-ending structure is described as an abnormal

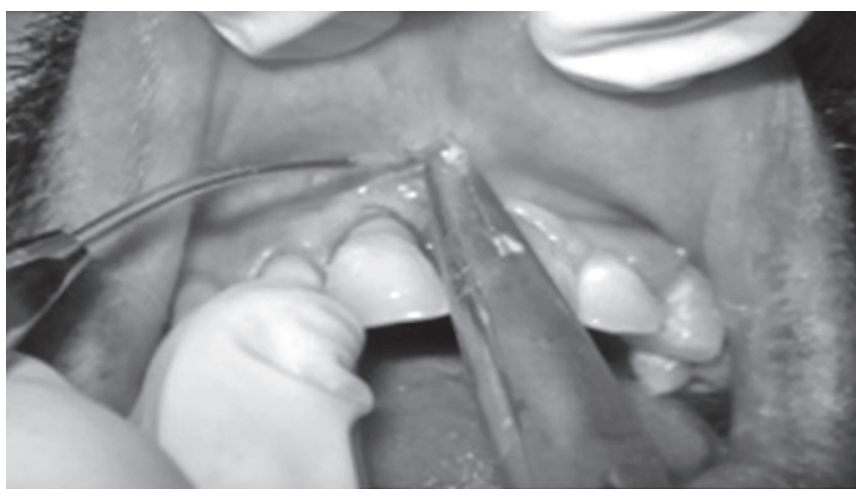

Fig. 8: Incisions made wide diode laser

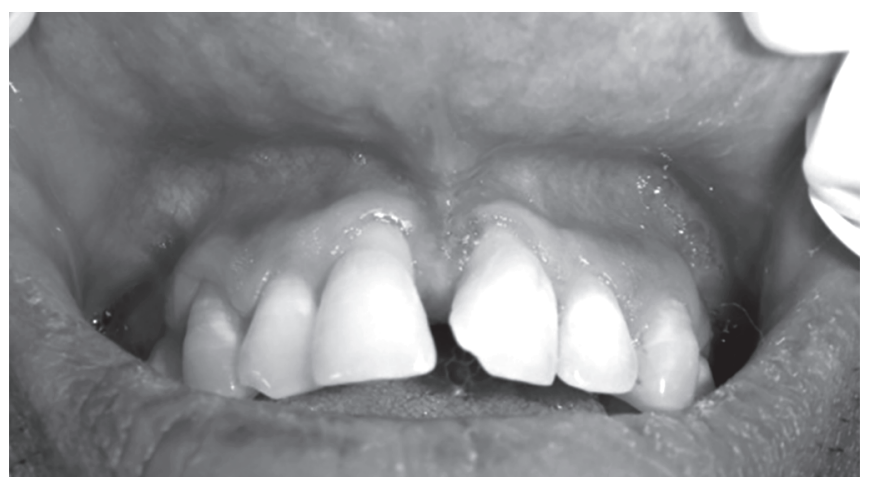

Fig. 10: View after 1 week postoperative

frenum that requires treatment. ${ }^{11,12}$ Frenectomy can be performed by the routine scalpel method technique, electrosurgery, or by using lasers. The conventional technique carries the routine risks of surgery like bleeding and patient compliance. ${ }^{9}$

Because of their capability to execute precise surgical incisions and excellent hemostatic control, lasers have been utilized in surgery, but, the results depend on the type of laser used and the tissue on which it is used (that is, whether the tissue has high collagen, hemoglobin, or water content). ${ }^{13,14}$ Lasers offer two important advantages over traditional scalpel surgery: firstly, it eliminates the use of sutures as there is rapid establishment of hemostasis, and secondly, the level of patient comfort is increased many folds. Some authors have also suggested that the direct effect on the surface of the targeted tissue is the creation of a coagulum of proteins, which produces a natural barrier that protects the underlying live connective tissue and increases the postoperative comfort. ${ }^{15-17}$ Thus, the use of laser has been reported as a safe and effective procedure for frenectomy procedure with the advantages of a shorter duration of surgery, simplicity of the procedure, the absence of postoperative infections, less pain, swelling, and the presence of a small or no scar. ${ }^{18}$

In the present study also, laser led to a considerable reduction in operating time. It also reduced the amount of local anesthetic used during the procedure and made it possible to avoid the placement of surgical sutures. Furthermore, tissue responded well to this approach with no postoperative complications.

\section{Conclusion}

An aberrant frenum can be removed by any of the techniques that have been discussed in the article. However, a functional and esthetic outcome can be achieved by a proper technique selection, 
based on the type of frenal attachment, clinician experience, and patient's choice. Every technique has its own merits and demerits, but further improvements can still be attempted.

\section{References}

1. Henry SW, Levin MP, Tsaknis PJ. Histologic features of the superior labial frenum. J Periodontol 1976;47(1):25-28. DOI: 10.1902/ jop.1976.47.1.25.

2. Galassini G, Marconcini S, Derchi G, et al. Labial frena and frenectomy: Clinical considerations. Ital Oral Surg 2007;4:7-14.

3. Placek M, Skach M, Mrklas L. Problems of the labial frenum attachment in periodontics. Il. Attempt to determine the resistance of periodontium to the influence of individual types of the labial frenum attachment. Cesk Stomatol 1974;74(6):401-406.

4. Mirko P, Miroslav S, Lubor M. Significance of the labial frenum attachment in periodontal disease in man. Part II. An attempt to determine the resistance of periodontium. J Periodontol 1974;45(12):895-897. DOI: 10.1902/jop.1974.45.12.895.

5. Tait $\mathrm{CH}$. Median frenum of upper lip and its influence on spacing of upper central incisor teeth. N Z Dent J 1929;25:116.

6. Koch G. Oral mucous lesions and oral surgery in children and adolescents. In: Koch G, Poulsen S, ed. Pediatric dentistry-A clinical approach. Munksgaard. Copenhagen: Munksgaard; 2001. pp. 399-407.

7. Huang WJ, Creath CJ. The midline diastema: A review of its etiology and treatment. Pediatr Dent 1995;17(3):171-179.

8. Dibart S, Karima M. Labial frenectomy alone or in combination with a free gingival autograft. In: Dibart S, Karima M, ed. Practical Periodontal Plastic Surgery. Germany: Blackwell Munksgaard; 2007. p. 53.
9. Devishree, Gujjari SK, Shubhashini PV. Frenectomy: A review with the reports of surgical techniques. J Clin Diagn Res 2012;6(9):1587-1592. DOI: 10.7860/JCDR/2012/4089.2572.

10. Goldman HM, Cohen DW. Periodontal Therapy, 6 th ed., United States of America: C.V. Mosby; 1980.

11. Olive G, Chaumanet G, Genovese MD, et al. Er,Cr:YSGG laser labial frenectomy: A clinical retrospective evaluation of 156 consecutive cases. Gen Dent 2010;58(3):e126-e133.

12. Rose LF, Mealey BL, Genco RJ, et al. Periodontics: Medicine, Surgery and Implants. Pennsylvania: Elsevier Mosby; 2004.

13. Parker S. Lasers and soft tissue: Periodontal therapy. Br Dent J 2007;202(6):309-315. DOI: 10.1038/bdj.2007.224.

14. Ishikawa I, Aoki A, Takasaki AA. Clinical application of erbium:YAG laser in periodontology. J Int Acad Periodontol 2008;10(1):22-30.

15. Guerry TL, Silverman S, Dedo HH. Carbon dioxide laser resection of superficial oral carcinoma: indications, technique, and results. Ann Otol Rhinol Laryngol 1986;95(6 Pt 1):547-555. DOI: 10.1177/000348948609500601.

16. Fisher SE, Frame JW, Browne RM, et al. A comparative histological study of wound healing following $\mathrm{CO}_{2}$ laser and conventional surgical excision of canine buccal mucosa. Arch Oral Biol 1983;28(4):287-291. DOI: 10.1016/0003-9969(83)90069-9.

17. Fenner J, Martin W, Moseley H, et al. Shear strength of tissue bonds as a function of bonding temperature: A proposed mechanism for laser-assisted tissue welding. Laser Med Sci 1992;7:39-43. DOI: 10.1007/BF02594047.

18. Cunha RF, Silva JZ, Faria MD. A clinical approach of ankyloglossia in babies: A report of two cases. J Clin Pediatr Dent 2008;32:277-282. DOI: 10.17796/jcpd.32.4.k553456640082145. 